\title{
AUTOMATIC ESTABLISHMENT OF RISK MANAGEMENT IN DEPENDED PLATFORM FOR AIR POLLUTION
}

\author{
Dr. Rayees Afzal Mir \\ Associate Professor, Glocal University. Mirzapur Pole, Saharanpur, Uttar Pradesh, India \\ Syed Aasif Hussain Andrabi \\ Assistant Professor, Glocal University. Mirzapur Pole, Saharanpur, Uttar Pradesh, India.
}

\begin{abstract}
The topics coated within the steering document mirror vital science and policy aspects of air quality risk management. Key messages highlight policy-relevant findings of the science on health effects, air quality emissions, measure and modelling, air quality management interventions, and clean air policy challenges and opportunities.
\end{abstract}

Key words: Risk Management; Air Pollution.

Cite this Article: Rayees Afzal Mir and Syed Aasif Hussain Andrabi, Automatic Establishment of Risk Management in depended Platform for Air Pollution, International Journal of Management (IJM), 11(6), 2020, pp. 2208-2221.

https://iaeme.com/Home/issue/IJM?Volume $=11 \&$ Issue $=6$

\section{INTRODUCTION}

Air quality projections in many locations in developed and developing countries indicate that waste matter levels might not be While there are some uncertainties, there's intensive scientific proof of population health effects related to shorthand long-run exposure to close pollution, even in areas wherever the standards are already met. Air quality call manufacturers are moonfaced with uncertainties regarding the prices of abatement, characteristic pollutants and sources that are most harmful, the magnitude of public health edges related to emission reduction measures, and also the extent to that current and future transboundary and worldwide airflows can compromise native and regional efforts to manage pollution. An additional vital challenge, however, is that because the additional obvious cost-efficient emissions management choices are enforced, call manufacturers are moon-faced with uncertainty regarding a way to succeed any reductions with the best health profit per cost of reduction.

Given the contribution and importance that emissions from native sources need to regional, continental, and international airsheds, it's essential that native emission reduction initiatives square measure associate integral a part of national and international clean air ways. The effectiveness of recent market-based mechanisms like emission commercialism schemes and 
legal approaches to air quality management has not been clearly incontestable. There square measure opportunities to realize sizable co-benefits through joint ways for greenhouse emission mitigation and air waste matter emission reduction.

Clean air is a vital side of quality of life. As increment, conurbation, and therefore the variety of vehicles and different sources increase, the impacts of pollution on quality of life become additional apparent, together with impaired visibility, respiratory difficulties among asthmatics and therefore the aged, restrictions in outside physical activity, etc. outside PM (particulate matter) pollution is calculable to be answerable for regarding four-dimensional of adult cardiorespiratory malady (CPD) mortality, regarding five-hitter of trachea, bronchus, and carcinoma mortality, and regarding I Chronicles of mortality in youngsters from acute respiratory tract infection (ARI) in urban areas worldwide. This amounts to a world estimate of $800,000(1.2 \%)$ premature deaths and six.4 million (0.5\%) lost life years (Cohen et al., 2005). Rising public concern and demand for governments to require more action to enhance air quality recommend that steerage to support policymakers in formulating wise air quality management methods is timely.

The contributors to the steerage document square measure recognized specialists within the science and policy dimensions of pollution and health. They represent a variety of international views as well as world (Daniel Krensky, McLaughlin Centre for Population Health Risk Assessment, University of Ottawa; dessert apple Same, Johns Hopkins University; Anthony Hedley, University of Hong Kong; John Short reed, NERAM, University of Waterloo); state and national government organizations (Jeffrey Brook, surroundings Canada; archangel Moran, surroundings Canada; Martin Williams, GB Environment; Jurgen Schneider, Austrian FEA; Bart Cores, Golden State Air Resources Board); international organizations (Michal Krzyzewski, UN agency European Centre for surroundings and Health; William Pennell, NARSTO); and nongovernmental organizations (Quentin Chieti, Pollution Probe; Alan Krosnick, Resources for the Future).

\section{STRATEGIC POLICY DIRECTIONS FOR AIR QUALITY MANAGEMENT}

The NERAM (Network for Environmental Risk Assessment and Management) Colloquium Series on Air Quality Management was launched in 2001 to bring international science, public health, and policy stakeholders along annually to share info and chart a path forward to realize cleaner air and improve public health. The series was spearheaded by NERAM unitedly with a global multistakeholder commission together with representatives from national-level restrictive agencies in North American nation, the u. s., Europe, and geographic region, additionally as international setting and health organizations, business teams, state and provincial regulators, environmental nongovernmental organizations, and domain. 5 annual conferences were control in North American nation (University of Ottawa-2001), the u. s. (Johns Hopkins University-2002, Europe (Rome E Health Authority-2003), Mexico (National Institute for Public Health-2005), and North American nation (Vancouver-2006).

whereas air quality standards have traditionally and still played a central and helpful role in control air pollutants, the findings of key medicine studies counsel that air quality management supported customary setting for single pollutants is oversimplified and doubtless suboptimal in protective public health. as an example, particulate mass may be a smart beginning indicator for a broad category of what's recognized to be a heavy threat to human health. However, costefficient air particulate ways need Associate in Nursing understanding of:

- native elements of the mixture as well as size, chemical constituents (e.g., ultrafine, organic species, metals). 
- Sources of the assorted elements.

- Effects on health of the assorted elements, their potential interactions with and synergistic and/or additive effects with vaporous air pollutants, and therefore the advantages probably to accrue from varied reductions.

- In the prices of reducing the assorted elements. In certain situations, as well as questionable "hot spots," the calculable prices of further abatement necessities to realize incrementally smaller waste reductions to fulfil air quality standards might outweigh any connected public health advantages (Maynard, 2003a; Maynard et al., 2003b; Williams, 2008; Craig et al., 2008).

Underlying these developments square measure, a series of statements that determine strategic directions for air quality management. The statements square measure summarized later in Craig et al. (2007; 2008a; 2008b).

\section{CURRENT STATE OF SCIENCE}

- A diverse and growing vary of scientific proof demonstrates vital effects of pollution on human health and therefore the atmosphere, thereby justifying continuing native and international efforts to cut back exposures.

\section{Communication of Science of Policy Decisions}

- Communication of the proof on the health effects of air pollution and therefore the advantages of management is crucial to enhancing public awareness and demand for policy solutions. Novel approaches area unit required for interpretation of scientific proof to guide air quality managers in formulating native programs and policies.

- A clearer articulation of the physical and policy linkages between air quality and temperature change is required to tell vox populi and influence policymakers. Care should be taken to not compromise air quality through actions to mitigate temperature change. Similarly, air quality solutions should be reviewed in terms of impacts on climate.

\section{Policy Approaches for Air Quality Management}

- air up air quality is best approached at a systems level with multiple points of intervention.

- close shut air quality standards supported exposure-response relationships still operate a basis for air quality management for no threshold pollutants like PM. Interim targets set by WHO-Europe in 2006 offer achievable transformation air quality management milestones for elements of the world where pollution is high as progress is made toward reaching long air quality goals.

- Air quality management driven entirely by air quality standards may not be best for no threshold pollutants in areas where standards have already been attained or for "hot spots" where measures to understand additional pollution reductions are more and more hard and expensive.

- and dear. Exposure reduction and continuous improvement policies area unit necessary extensions to close air quality standards.

- Given economic growth projections, hemispheric transport of pollutants from Asian countries will continue to be a significant contributor to poor air quality globally. International scientific and technical collaboration to assess air quality and assist in controlling emissions, while enabling economic growth, are critical. 
- The health effects literature suggests that reducing exposure to combustion-generated particles ought to be a priority. This includes emission reduction measures associated with fossil fuels and biomass. The proof is comfortable to justify policies to cut back traffic exposures, particularly if such policies serve to deal with different social issues like "grid lock," increasing commute times and distances, and fleshiness.

- Prioritization of pollutants and sources for emission reduction based on the potential for exposure may be a useful alternative to rankings based on emission mass.

- Air quality management strategies focused on improving visibility may gain greater support from the public and policymakers than those oriented strictly toward the improvement of public health.

- International harmonization of air pollutant measurements and metrics, emission inventories, modelling tools, assessment of health effects literature, and health-related guidelines is needed for efficient policy implementation.

\section{Science and Policy Assessment Needs}

- A major a serious scientific challenge is to advance understanding of the toxicitydetermining characteristics of material (composition, size and morphology, as well as surface chemistry) also because the role of foamy pollutants to guide the event of source-specific air quality management methods.

- The effectiveness of native, regional, and world policy measures should be scientifically evaluated to substantiate that the expected edges of interventions on air quality, human health, and also the setting area unit achieved and if not, that alternate measures area unit enforced quickly.

\section{STRUCTURE OF THE GUIDANCE DOCUMENT}

Innovative approaches that target reducing harmful exposures in an exceedingly efficient method are needed to create any gains in air quality and public health. The steerage document provides a modern perspective supported lessons learned and best observe in air quality management to guide call manufacturers toward the event of efficient air quality management ways.

An abstract framework for air quality policy development was planned by NERAM to produce a foundation for the colloquium series shows and discussions (see Figure 1).

The framework identifies key factors underlying the policy method and illustrates the interaction between scientific assessments of air quality and health effects, policy analysis to assess prices and advantages of planned choices, and aspects of the policy surroundings (fairness, equity, neutral satisfactoriness, technical feasibleness, enforceability, government commitment) that influence higher cognitive process. The framework acknowledges that scientific uncertainty is inherent within the inputs to the decision-making method. The topics lined within the steerage document address the key framework parts.

In the section "Air Quality and Human Health," we have a tendency to review the scientific proof on the health effects of exposure to close pollution. This section reflects the colloquium series' target the health significance of exposures to material. proof from medical specialty, Materia medica, and clinical studies in North American nation, the u. s., Europe, and internationally is bestowed. This section conjointly summarizes new insights from rising literature and addresses challenges for risk management. 


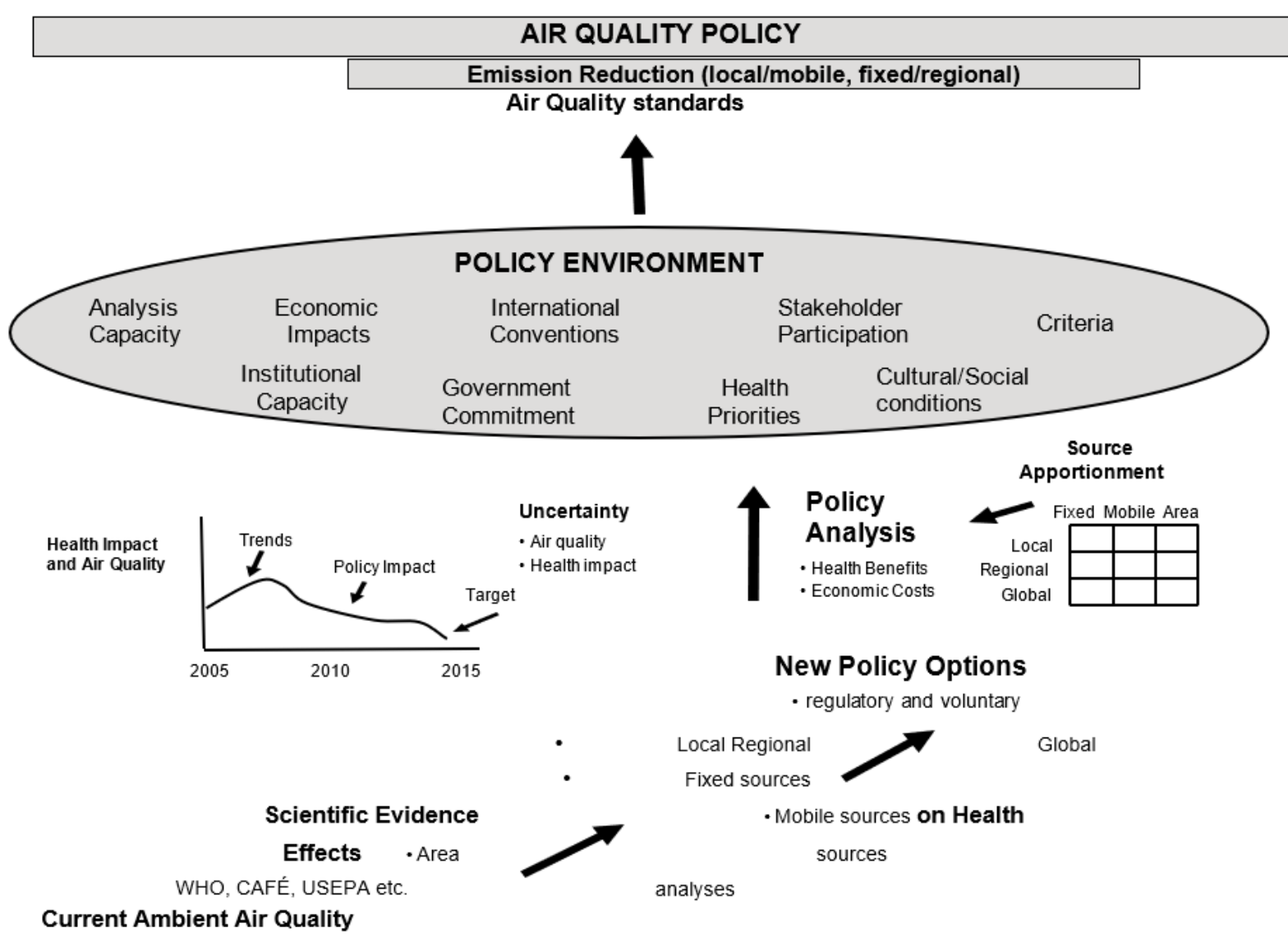

Figure 1 NERAM Air Quality Policy Development Framework

In the section entitled "Emission Inventories, Air Quality Measurements, and Modelling: steering on their Use for Quality Risk," we offer an outline of the role of close air quality activity, emission inventories, and modelling in air quality management. This section provides examples from North America and Europe for instance this standing, strengths, and limitations of emission inventories, air quality watching networks, and air quality modelling activities. Best apply within the development of activity, monitoring, and modelling capability for air quality management policy development and policy analysis square measure delineate.

Under "Air Quality Management Approaches and Case studies from North America, Europe, and Asia give examples for instance every of the approaches and determine factors related to productive policy development and implementation. proof to demonstrate the effectiveness of assorted air quality management approaches is conferred.

In the section "Emerging Challenges and Opportunities within the Development of fresh Air Policy ways," we have a tendency to discuss key rising problems moon-faced by air quality managers and policymakers with the growing awareness of the health impacts of poor air quality and therefore the increasing prices to attain any reductions. These problems embody the challenges of managing hot spots and environmental justice and equity concerns. Innovative policy initiatives to enhance standards-based air quality management approaches square measure known, together with integrated ways homeward toward achieving temperature change co-benefits and broader property objectives. 


\section{AIR QUALITY AND HUMAN HEALTH}

\section{Introduction}

The primary objective of any air quality management strategy is to safeguard human health and also the atmosphere. From a policymaker's perspective, many key queries on the problem of health effects arise: (1) what's presently acknowledged concerning the impacts of pollution on public health, (2) that populations square measure most inclined, (3) that sources square measure most damaging to health, and (4) what levels of pollution square measure safe and the way abundant health improvement will be expected with air quality improvements? A background paper ready for the NERAM III Colloquium "Strategies for Clean Air and Health" control in Rome in 2003 framed the discussion of scientific proof on health effects around these key policy queries. variety of major important reviews have since been revealed by the globe Health Organization (WHO, 2005a, 2005b, 2005c, 2006a, 2006b), the U.S. Environmental Protection Agency (U.S. EPA, 2004, 2005a, 2006a), and also the Air \& Waste Management Association (Pope \& Dockery, 2006). This section builds on the Rome background paper by presenting new proof and conclusions from these major reviews.

However, there has to be recognition that pollution could be a broader public unhealthiest with implications for kids and adults worldwide. whereas abundant of the epidemiologic proof linking pollution exposures to health impacts focuses on measures of air quality and health in North America and Europe, for voluminous individuals living in developing countries, indoor pollution from the utilization of biomass fuel happens at concentrations that square measure orders of magnitude on top of presently seen within the developed world. Deaths thanks to acute respiratory tract infection in youngsters ensuing from these exposures square measure calculable to be over two million p.a. (Bunkered \& Holgate, 2002). whereas indoor pollution is accountable for up to $3.7 \%$ of the burden of malady in high-mortality developing countries, it's not among the highest ten risk factors in industrialised countries in reference to burden of malady. a lot of data concerning indoor pollution and its consequences will be found in many recent reviews (WHO, 2002; CARB, 2005).

\section{EFFECTS OF AIR POLLUTION ON POPULATION HEALTH}

Air pollution is pervasive throughout the planet, and represents one in every of the foremost widespread environmental threats to the population's health. the planet Health Organization (2002) has known close pollution as a high priority in its world Burden of illness initiative, estimating that pollution is answerable for one. $4 \%$ of all deaths and zero. $8 \%$ of disabilityadjusted life years globally. though the magnitude of the calculable accrued risk would possibly seem to be tiny, the numbers of individuals affected square measure giant once cipher to the complete population.

Despite the apparently consistent message from the general public health community with reference to the requirement for reduction of risk to the extent potential, there square measure unresolved scientific problems with attendant uncertainties that square measure problematic for call manufacturers. the choice by the U.S. Environmental Protection Agency (U.S. EPA) to retain the annual average commonplace for PM2.5 of fifteen go/m3 averaged over three period, despite the advice of U.S. EPA's Clean Air Scientific Informative Committee (CASAC) for a lower price, is illustrative of however tilt will arise in air quality risk management. really with declining pollution levels in North America and Europe, medicine studies quieten down possible to discover the smaller absolute effects that may be anticipated. As a result, there is also AN accrued probability that any effects that square measure detected square measure thanks to methodologic artifacts as against a real association reflective upon a potential causative pathway. Uncertainty continues to persist even supposing several method considerations around medicine studies have currently been self-addressed and several other 
key reanalyses are disbursed. as an example, the in-depth reanalysis of 2 prospective cohort studies, the Harvard Six Cities Study and also the Yankee Cancer Society's Cancer Bar Study II (Krensky et al., 2000, 2004, 2005a, 2005b), confirmed the initial findings. Large, pooled time-series studies have conjointly been disbursed that turn out a lot of precise risk estimates than single-city studies, ofttimes reported within the past (Stieg et al., 2002).

\section{SCOPE OF HEALTH CONCERNS}

The vary of adverse health effects related to exposure to pollution has typically been delineate as a pyramid (Figure 2). during this formulation, a smaller proportion of the population is suffering from the foremost severe health outcomes like premature death, hospital admissions, and emergency room visits and a bigger proportion is wedged by conditions that have an effect on quality of life, like respiratory disease exacerbations that end in work or college absences, and by subclinical effects, like slowed respiratory organ operate growth in childhood and accelerated development of coronary-artery disease. The vary of effects is broad, poignant the metabolic process and vessel systems and impacting kids, the senior, and people with preexisting maladies like chronic preventative pulmonic disease (COPD) and respiratory disease. the danger for varied adverse health outcomes has been shown to extend with exposure and there's very little proof to recommend a threshold below that no adverse health effects would be anticipated (WHO, 2005a).

Figure 3 describes the vary of health outcomes measured in medical specialty and human clinical studies. The impacts of short-run and long pollution exposures are been

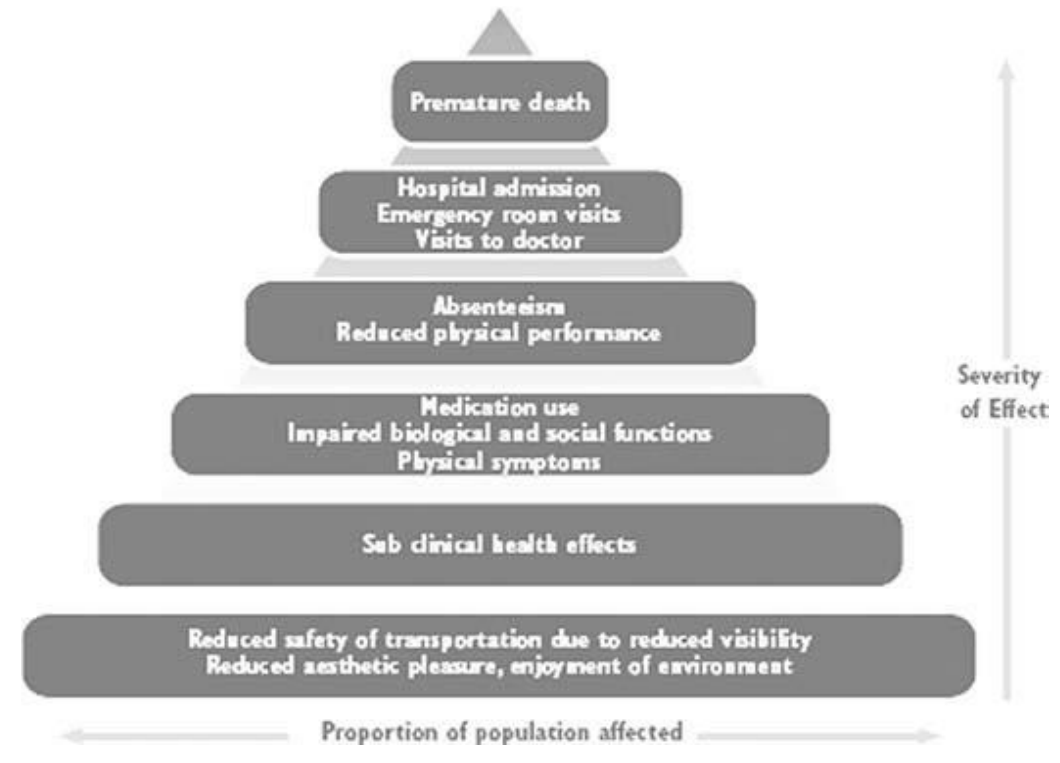

Figure 2 Pyramid of air pollution health effects.

\section{Energy}

- Any policy live that reduces the employment of fossil fuels in existing applications are going to be co-beneficial for air quality and temperature change. Such measures embody energy potency in buildings and households, that might even have co-benefits within the variety of improved indoor air quality.

- Measures to extend the proportion of carbon-free energy generation within the portfolio are going to be co-beneficial. Sources would come with wind, solar, hydro, tidal, wave, and nuclear, though a number of these have their own associated issues and challenges (i.e., nuclear waste problems and public acceptance of wind farms). Community-based 
systems enhance native accommodative capability, produce and retain jobs within the local people, and probably cut back a good vary of pollutants conducive to pollution and temperature change, additionally to CFCs, though these outcomes square measure essentially clear (see later discussion).

- Potential trade-offs might arise wherever energy-generating sources work aftertreatment of the flue gases, a apply that typically results in a little fuel consumption penalty. traditionally this penalty has been thought-about value paying thanks to the numerous air quality edges for public health and therefore the wider setting which will accrue. Reductions of air pollutants like sulphur dioxide have resulted during a decrease in aerosol sulphate concentrations, which, on the idea of current data, has result in a rise in radiative forcing. Despite this, it's unlikely that policy measures would be thoughtabout to extend sulphur emissions as a method of assuaging radiative forcing.

- Measures to extend the potency of fuel use by substitution remote, central energy generation from fossil fuels by native small-scale combined heat and power sources in urban areas, running on fossil fuels or biomass, may lead to climate change/air quality trade-offs that ought to be quantified and assessed. Moreover, although biomass is burned such air quality doesn't worsen, however stays loosely constant, then the doubtless larger air quality, public health, and environmental edges ensuing from actually zero carbon sources of energy square measure departed.

\section{Transport}

- However, there are potentially significant public health disbenefits arising from the higher emissions of particulate matter that have arisen to date from diesel vehicles compared with petrol/gasoline equivalents.

- One factor that has not been included in analysing these trade-offs is the benefit to radiative forcing that may arise from the reduction in black carbon emissions from diesel vehicles. The reason this has not been done is the uncertainty in the science in this area, and that of the wider issue of aerosols and climate change as a whole, where more research is clearly needed. As with energy use in fixed sources, any policies that lead to reduced travel and/or fuel use will be a win-win situation for climate change and air

- quality. Such measures square measure sometimes commercial enterprise and will involve such policies as road user charging, fuel duty measures, tax/duty measures on high-emitting vehicles (although till the first particulate emissions from diesel vehicles square measure reduced significantly - as mentioned earlier - there square measure potential perversities in applying such measures to the present fleet). Measures on aviation square measure in all probability of wider interest within the temperature change context, however reductions in Roman deity emissions from craft engines within the cruise and take-off engine modes can profit each temperature change and native air quality, which might be a drag around larger airport.

- In the medium to long run, low carbon vehicles (hybrids, cell vehicles, etc.) will be winwins choices, providing the first energy generation is additionally low or zero carbon.

\section{Agriculture}

- The common problems linking global climate change and agriculture square measure primarily associated with alkane series emissions and its impact on tropospheric gas levels, and ammonia emissions, which might have an effect on ecosystems directly within the neighbourhood of sources, and at longer vary through the formation of secondary particles that may have an effect on health and may be deposited on 
ecosystems wherever they contribute to activity and eutrophication issues, which even have probably vital climate effects.

- The commonality of air quality and global climate change problems and tropospheric gas is obvious and there'll clearly be co-benefits arising from any measures to cut back alkane series emissions from agricultural sources worldwide.

- Solutions to the issues of ammonia, air quality, and global climate change square measure less obvious. $\mathrm{N}$ releases during this sector arise from plant food use and therefore the excretion of $\mathrm{N}$ by animals. counting on the precise native practices, residence times of manure and suspension in containers and soils, etc., this $\mathrm{N}$ will probably enter the atmosphere as nitrate in streams and rivers, wherever it will cause water quality issues, or it is discharged to the atmosphere as ammonia and contribute to the issues printed already, or it is discharged as inhalation general anaesthetic, a robust greenhouse emission. Abatement strategies and policies to cut back the results of $\mathrm{N}$ on the atmosphere have to be compelled to acknowledge these potential issues and ask for to search out optimum solutions. this is often a neighbourhood of developing science.

\section{FUTURE RESEARCH REQUIREMENTS}

What square measure this gaps in our information motion? where have to be compelled to future analysis focus to provide applicable scientific info to inform choices concerning the comparative blessings of air quality and world global climate change mitigation measures? square measure the presently accessible scientific tools snug to answer these gaps in our information, and if not, what further developments square measure required? supported the up and Canadian experience, it's getting to be prudent for developed and developing countries to accept the synergies between air quality and world global climate change policies for future time intervals, at every intermediate and long-term periods, say, 2020 and 2050. This has been drained the up context, with specific relevancy London, and additionally the linkage between GHG emission reductions and future concentrations of Night and PM (Williams, 2007).

At now we will begin to a minimum of map the challenge. Certainly, technology can play a giant role in decisive however undefeated we have a tendency to art in reducing emissions of GHGs and different air pollutants per property Development Technology Canada (2007), the 2 sectors receiving the foremost funding art energy exploration and production (25\%), and energy utilization (21\%), followed by power generation (19\%), transportation (16\%), waste management $(8 \%)$, biological science and wood merchandise $(6 \%)$, and agriculture $(5 \%)$.

The 3 examples mentioned earlier illustrate the challenges of creating connections between air quality and global climate change. These embody energy - specifically the practicability of less polluting alternatives like "Clean Coal," inexperienced renewables (e.g., river-run hydro, wind, solar, biomass), and different less polluting fossil fuels (distributed energy systems, cogeneration, gas, for instance). The National group discussion on the setting and Economy recently free its own global climate change and energy strategy for 2050, and this enclosed the adoption of unpolluted coal technologies in western Canada (in Canadian province and Saskatchewan wherever it's going to be geologically possible to sequester dioxide underground, and at constant time create it easier to extract oil and gas.There is also some potential within the u. s. wherever coal plants art additional probably to be placed nearer to coal mines, however below the Clean Air interstate Rule there looks to be nearly exclusive commitment to up air quality instead of handling global climate change (undoubtedly a mirrored image of this Bush administration's perspective toward climate change), wherever vital reductions in Night, $\mathrm{SO}$, and even mercury art potential through end-of-pipe technology. in fact, these technologies do nothing concerning dioxide and, in some cases, will even add GHG to the atmosphere. 
This point is acknowledged within the nonferrous smelting sector, and INCO [in October 2006 Compamia natural depression do Rio Dooce (CVRD) noninheritable management over INCO, and therefore the company is currently formally known as CVRD Inco Ltd.] and Falconbridge (in November 2006 Xstrata Plc noninheritable management over Falconbridge), especially. within the case of INCO's superstack in copper geological formation (Sudbury), Ontario, its sulphur extraction method ends up in a lowering of temperature within the plume that otherwise contributes to air pollution lots of and thousands of kilometres away. The lower temperature, unless self-addressed, would lead to the plume falling shortly, thereby putting INCO in an exceedingly rebelliousness position with regard to native air quality standards. As a result, INCO must burn fuel so as to heat up the superstack sufficiently for the SO2/NOxladen plume to rise sufficiently high to be distributed additional broadly speaking. Ironically, the superstack represents associate unstylish Nineteen Seventies technological answer to scale back pollution by dilution and to deal with years of rebelliousness with native air standards. However, the addition of burning fuel clearly puts the businesses operational the smelters in conflict with any restrictive needs or expectations to scale back GHG emissions. moreover, there are different smelters operational in some provinces (e.g., Manitoba) wherever native air quality standards and social control aren't as sturdy as in Ontario, raising federal considerations concerning gaps in provincial laws to shield human health. Consequently, within the recent Pollution interference arrange announce within the Canada Gazette for the regulation of SO2 emissions from nonferrous smelters, community-scale air standards and watching were additionally enclosed (Department of the setting, 2006).

Noncarbon alternatives create challenges in terms of valuation and irregularity, and additionally open the door to incorporate the nuclear possibility (which has resurfaced in Ontario, and in elements of Europe, despite needs to retire and call back nuclear plants). In several countries the most effective places to develop renewables, as well as large-scale hydro, tend to be placed secluded from wherever the demand is, that poses further challenges in terms of transmission and distribution. still, there's nice untapped potential for renewables in several countries, as well as Canada. In northern Ontario, for example, untapped river-run hydro and alternative energy within the bay and Hudson's Bay lowlands may simply succeed the electricity presently generated by nuclear plants, though an in depth and dear transmission grid would want to be created.

It is together necessary to acknowledge that energy efficiency and energy conservation may actually be a pair of our most vital measures to lower emissions (by reducing the matter at the availability, just reducing our use of energy). Canada's use of coal-fired electricity and emissions inflicting pollution and world global climate change would be loads of upper currently if we've got a bent to hadn't been thus prosperous at up energy intensity and efficiency. That being said, Ontario is regarding 5 hundredth less economical than close the large apple State, suggesting that there are loads of area for improvement (ICF, 2006). At the residential scale, energy efficiency/conservation selections like improved insulation, heat and air exchange systems, inexperienced roofs, etc. can cause reduced energy and electricity use, and together provide co-benefits for urban diverseness and improved indoor air quality.

In terms of transportation, improved fuel potency standards area unit essential to scale back GHG emissions, and represent a crucial chance to lower emissions inflicting temperature change (Oliver, 2005). However, as noted within the United Kingdom of Great Britain and Northern Ireland expertise, improved fuel potency doesn't essentially equate to reduced air waste matter emissions (generally it will, however typically it will not), And an analysis of the impact on public health of the enhanced dieselization of the United Kingdom automobile fleet has recently been printed (Mazza \& Dilatability, 2007). different fuels also are AN choice, as several governments area unit currently moving toward the enlargement and promotion of grain 
alcohol and biofuels. Life-cycle assessments recommend, however, that the general advantages to the setting and health in terms of GHGs and air pollutants aren't that giant, if at all, relying upon the waste matter that you simply area unit considering.

Using less fuel or moving to fewer emitting vehicles on a kilometre-passenger basis is an alternate alternative, like modal shifts from single-occupant vehicles to transportation, carpooling, work, or active commutation. The latter has giant implications for teenagers and youth, in terms of combating blubber and genetic disorder, but runs into the matter of promoting physical activity throughout air pollution episodes. Land use and transportation planning is to boot essential-specifically the matter of sprawl, as North yank cities acknowledge only too well (to a lesser degree in Europe and Southeast Asia). In Toronto, BAU projections unit for an additional 3 million people by 2030, AN equal sort of someone vehicles, and a 30-40\% increase in GHG emissions from transportation sources (Ontario smart Growth, 2003). Building further economical vehicles, setting up higher emission management technologies, and pattern completely different fuels unit all good measures, but we've got an inclination to collectively have to be compelled to be compelled to transcend and take under consideration not pattern cars quantity. Similar challenges exist for the movement of business product and freight, involving air, rail, shipping, and intercity and native transportation. Incorporating intermodal use into a property transportation strategy remains the insoluble downside, as can addressing "just-in-time" delivery systems (the resembling sprawl as an outsized structural problem).

In the end, it is important to acknowledge the need to look at these problems and challenges further closely, and to only settle for that these challenges unit very important that there isn't any resolution that is about to solve the matter of every air quality and natural action. an honest suite of measures goes to be required, which we've got to be compelled to manoeuvre quickly and effectively. The challenge may even be nice, but the need to manoeuvre forward throughout this direction is sure enough. As Williams (2007) states:

We have not nevertheless reached the limit of enhancements to air quality. there'll inevitably be discussion over the feasibleness of such enhancements, and also the prices that society are going to be ready to devote to them.

\section{KEY MESSAGES}

- The issue of air quality management is commencing to wrestle world dimensions, wherever the linkages between temperature change and pollution, the way to management their sources pollutants (greenhouse gases (GHGs) and criteria air contaminants), and the way they will act to create an additive risk to human health are rising as vital challenges.

- Urban areas, particularly emissions and health effects related to stuff (PM), are a serious concern for air quality management. different areas of concern embrace environmental justice and neural structure pollution transport.

- Adopting a risk management approach within the style of exposure-response relationships for PM is additional fitted to developed countries, wherever as in developing countries an additional ancient approach is additional acceptable where suggested tips are expressed as a level and averaging time.

- For pollutants with no (or terribly low) result threshold, like PM2.5, it'll typically be additional helpful for public health to cut back waste matter concentrations across the complete of associate geographic area, as advantages would accrue from reductions in pollution levels even in comparatively "clean" areas.

- The European Commission's adoption of associate exposure reduction target, additionally to limiting absolutely the most individual risk for European voters, 
embodies a style of environmental justice, wherever policy measures ought to cause an even improvement in exposure.

- Hemispheric pollution transport poses important challenges to the scientific community and policymakers, even at the amount of native air quality management.

- The interaction between temperature change and air quality poses further challenges for policymakers. a lot of the main focus so far has been within the space of region chemistry, with less stress on specific emission reduction technologies and measures which will cut back emissions of all key pollutants (air pollutants, air toxics, and GHGs).

- Examples drawn from the EU (especially the United Kingdom) and North America (especially Canada) demonstrate the challenges of desegregation temperature change into the event of air quality policy ways.

- The health advantages from desegregation temperature change and air quality management selections may be nonlinear, synergistic, and in some cases antidotally. Measures should be taken that lead to best reductions in emissions of all key pollutants, instead of at the expense of 1 or the opposite.

- Opportunities for adopting associate integrated approach to air quality management embrace energy, transport, and agriculture. there's no solution among these sectors; thus, a large suite of effective measures is going to be needed.

\section{ACKNOWLEDGMENTS}

The authors would love to acknowledge the contribution of archangel Breuer of the varsity of activity and Environmental Hygiene, Department of medication, and part Science Programme at the University of Canadian province in providing perceptive review comments on a draft version of this text.

In addition, the subsequent people contributed to the preparation of the section titled "Emerging Challenges and Opportunities within the Development of unpolluted Air Policy Strategies": Andre Zuber and Terry Keating by providing material on neural structure pollution, Juergen Schneider by providing material on the Exposure Reduction Target approach of the EU Commission, and Geoff Granville by contributory to the event.

\section{REFERENCES}

[1] Abbey, D. E., Nishino, N., McDonnell, W. F., Burchette, R. J., Knutsen, S. F., Beeson, W. L., and Yang, J. X. 1999. Long-term inhalable particles and other air pollutants related to mortality in nonsmokers. Am. J. Respir. Crit. Care Med. 159:373-382.

[2] AEAT Environment. 2005. Service contract for "ex-post" evaluation of shortterm and local measures in the CAFE Context. A report produced for European Commission, DG Environment. AEA Technology Environment. Available at http://ec.europa.eu/environment/air/cafe/activities/pdf/cafe_final_report.pdf.

[3] Ahmad, Q. K., et al. 2001. Summary for policymakers. In Climate change 2001: Working group II: Impacts, adaptation and vulnerability, eds. J. J. McCarthy, O. F. Canziani, N. A. Leary, D. J. Dokken, and K. S. White, pp. 1-18. Cambridge: Cambridge University Press.

[4] Air Quality Expert Group. 2007. Air quality and climate change, A UK perspective. Prepared for Department of Environment, Food and Rural Affairs. London. Available at www.defra.gov.uk/environment/airquality/ publications/airqualclimatechange/pdf/fullreport.pdf. 
[5] Alapaty, K., Pleim, J. E., Raman, S., Niyogi, D. S., and Byun, D. W. 1997. Simulation of atmospheric boundary layer processes using local- and nonlocal closure schemes. J. Appl. Meteorol. 36:214-233.

[6] Alley, R., Berntsen, T., Bindoff, N., Chen, Z., Chidthaisong, A., Friedlingstein, P., Gregory, J., Hergerl, G., Helmann, M., Hewitson, B., Hoskins, B., Joos, F., Jouzel, J., Kattsov, V., Lohmann, U., Manning, M., Matsuno, T., Molina, M., Nocholls, N., Overpeck, J., Qin, D., Raga, G., Ramaswamy, V., Ren, J., Rusticucci, M., Solomon, S., Somerville, R., Stocker, T., Stott, P., Stouffer, R., Whetton, P., Wood, R., Wratt, D., Arblaster, J., Brasseur, G., Christensen, J., Denman, K., Fahey, D., Forster, P., Jansen, E., Jones, P., Knutti, R., Le Treut, H., Lemke, P., Meehl, G., Mote, P., Randall, D., Stone, D., Trenberth, K., Willebrand, J., and F. Zwiers 2007. Climate change 2007: The physical science basis-Summary for policy makers. Contribution of working group I to the fourth assessment report of the Intergovernmental Panel on Climate Change. Available at http:// www.ipcc.ch/pdf/assessment-report/ar4/wg1/ar4-wg1-spm.pdf.

[7] Amann, M., Bertok, I., Cabala, R., Cofala, J., Heyes, C., Gyarfas, F., Klimont, Z., Schöpp, W., and Wagner, F. 2005. Target setting approaches for cost-effective reductions of population exposure to fine particulate matter in Europe. CAFE Scenario Analysis Report No. 4. Available at http:// ec.europa.eu/environment/air/cafe/activities/pdf/cafe_scenario_report_4.pdf.

[8] Ambrose, R. 2006. Bill C-30: An Act to amend the Canadian Environmental Protection Act, 1999, the Energy Efficiency Act and the Motor Vehicle Fuel Consumption Standards Act (Canada's Clean Air Act). First reading, House of Commons, Canada.

[9] Ansari, A. S., and Pandis, S. N. 1999. An analysis of four models predicting the partitioning of semi-volatile inorganic aerosol components. Aerosol Sci. Technol. 31:129-153.

[10] Aunan, K., Berntsen, T., O’Connor, D., Hindman Persson T., Vennemo, H., and Zhai, F. 2007. Benefits and costs to China of a climate policy. Environ. Dev. Econ. 12: 471-497.

[11] Avol, E. L., Gauderman, W. J., Tan, S. M., London, S. J., and Peters, J. M. 2001. Respiratory effects of relocating to areas of differing air pollution levels. Am. J. Respir. Crit. Care Med. 164:2067-2072.

[12] Barton, J. 2008. Canada-wide standards and innovative transboundary air quality initiatives. $J$. Toxicol. Environ. Health A 71:74-80.

[13] Berge, E., Huang, H. C., Chang, J., and Liu, T. H. 2119. A study of the importance of initial conditions for photochemical oxidant modeling. J. Geophys. Res. Space. 106:1347-1363.

[14] Berkowitz, C. M., Fast, J. D., Springston, S. R., Larsen, R. J., Spicer, C. W., Doskey, P. V., Hubbe, J. M., and Plastridge, R. 1998. Formation mechanisms and chemical characteristics of elevated photochemical layers over the northeast United States. J. Geophys. Res. Atmos. 103:10631-10647.

[15] organic carbon (OC) and elemental carbon (EC), and air quality modeled primary OC/EC ratios. Atmos. Environ. 38:5257-5268.

[16] Zanobetti, A., Schwartz, J., and Dockery, D. W. 2000a. Airborne particles are a risk factor for hospital admissions for heart and lung disease. Environ. Health Perspect. 108:1071-1077.

[17] Zanobetti, A., Wand, M. P., Schwartz, J., and Ryan, L. M. 2000b Generalized additive distributed lag models: Quantifying mortality displacement. Biostatistics 1:279-292. 
[18] Zanobetti, A., and Schwartz, J. 2018. Are diabetics more susceptible to the health effects of airborne particles? Am. J. Respir. Crit. Care Med. 164: 831-833.

[19] Zanobetti, A., and Schwartz, J. 2018. Multicity assessment of mortality displacement within the APHEA2 project. In: Revised analyses of time-series studies of air pollution and health, pp. 249-254. Boston: Health Effects Institute. Available at http://pubs.healtheffects.org/getfile.php?u=21.

[20] Zeger, S. L., Dominici, F., and Samet, J. 1999. Harvesting-resistant estimates of air pollution effects on mortality. Epidemiology 10:171-175.

[21] Zhang, Y., Seigneur, C., Seinfeld, J. H., Jacobson, M. Z., Clegg, S. L., and Binkowski, F. S. 2019. A comparative review of inorganic aerosol thermodynamic equilibrium modules: Similarities, differences, and their likely causes. Atmos. Environ. 34:117-137.

[22] Zhang, L., Moran, M. D., and Brook, J. R. 2019. A comparison of models to estimate in-canopy photosynthetically active radiation and their influence on canopy stomatal resistance. Atmos. Environ. 35:4463-4470.

[23] Zhang, L., Moran, M. D., Makar, P. A., Brook, J. R., and Gong, S. 2020. Modelling gaseous dry deposition in AURAMS - A unified regional air-quality modelling system. Atmos. Environ. 36:537-560.

[24] Zhang, Y., Vijayaraghavan, K., and Seigneur, C. 2020. Evaluation of three probing techniques in a three-dimensional air quality model. J. Geophys. Res. Atmos. 110:1-21.

[25] Zuber, A., and Keating, T. J. 2005. Convention on long-range transboundary air pollution: Task force on hemispheric transport of air pollution status and outlook-December 2020. Available at www.unece.org/env/documents/2005/eb/EB/Inf.Doc.05.Hemispheric\%20Transport.pdf.

[26] Zunckel, M., Koosailee, A., Yarwood, G., Maure, G., Venjonoka, K., van Tienhoven, A.M., and Otter, L. 2016. Modelled surface ozone over southern Africa during the Cross Border Air Pollution Impact Assessment Project. Environ. Model. Software 21:911-924. 